\title{
Air quality, respiratory health and wood use for women converting from low- to high-efficiency stoves in rural Kenya
}

\author{
K.Critchley ${ }^{1}$, K. Teather ${ }^{2}$, H. Hughes ${ }^{3}$, A. MacDonald ${ }^{1}$ \\ \& M. Gibson ${ }^{4}$ \\ ${ }^{1}$ School of Nursing, University of Calgary-Qatar, Qatar \\ ${ }^{2}$ Department of Biology, University of Prince Edward Island, Canada \\ ${ }^{3}$ School of Nursing, University of Prince Edward Island, Canada \\ ${ }^{4}$ Department of Process Engineering and Applied Science, \\ Dalhousie University, Canada
}

\begin{abstract}
Over $90 \%$ of women in rural Kenya rely on biomass to meet their cooking and heating needs and most of these women use the traditional three-stone cookstove. In the fall of 2011, Farmers Helping Farmers, a non-government organization from Prince Edward Island, installed more efficient cookstoves for a group of women in the Kiirua region, about four hours north of Nairobi. We assessed air quality, wood use, and the respiratory health of women before (summer, 2011) and after (summer 2013) the new stoves were installed. Although we found no difference in the concentrations of volatile organic compounds before and after the installation of stoves, women used less fuel and spent less time exposed to poor quality air. We documented significant improvements in the respiratory health of women after new stoves were installed, both in self-reported illnesses over the previous six months and through spirometry tests.
\end{abstract}

Keywords: particulate matter, cookstoves, respiratory health, firewood, air quality, biomass fuel.

\section{Introduction}

It is estimated that more than $50 \%$ of the world's population, and up to $90 \%$ of rural households in developing countries, still use biomass as their primary fuel 
source [1]. The combustion of biomass is known to release a large number of toxic substances and carcinogenic compounds, leading to indoor air pollution [2] and making the use of biomass as a household fuel the most important source of indoor air pollution on a global scale [3]. The World Health Organization estimated that 1.6 million people die each year as a result of indoor air pollution [4].

In Kenya over $90 \%$ of rural households rely on firewood for cooking and heating [5]. The traditional stove, often consisting of three stones arranged in a triangle, is commonly used for cooking [6]. The cookhouses are often separate structures from the rest of the home, usually small and lacking a chimney with no other source of ventilation other than the door and sometimes a window. Women who are responsible for most of the cooking, and preschool-age children who often accompany women, are more often exposed to pollutants released from the combustion of biomass.

The effluents of wood smoke from incomplete combustion are thought to contain over 200 toxins and volatile organic compounds (VOCs), all of which are almost entirely within the inhalable size range [7]. There is substantial evidence from studies done in developing countries that exposure to high levels of indoor air pollution results in increased incidence of COPD in women, acute respiratory infections (ARIs) in children, and increasing evidence suggests that perinatal mortality, low birth weight, asthma, tuberculosis, and cancer of the upper airway are also linked to exposure to biomass smoke [8-10]. Other negative effects associated with using wood as fuel stem from time constraints imposed by the increased time in cookhouses and collecting wood. This time cannot be used for other activities, and quality of life declines. Women collecting wood are also subject to injuries to backs and necks [11] and may risk becoming victims of violence and rape [12].

Installation of more energy-efficient stoves by Farmers Helping Farmers (FHF), a nongovernment group having worked in the area for more than 30 years, provided a unique opportunity to examine potential differences in air quality and the lives of women before and after switching to better quality stoves. In addition to reducing the amount of wood required for heating and cooking, these stoves were equipped with a chimney to carry much of the smoke outside the house. Our objectives were to assess (a) indoor air quality, (b) the respiratory health of the women, and (c) time spent in the cookhouse and collecting wood before and after the installation of energy-efficient stoves in rural Kenya.

\section{Methods}

This research was conducted in the rural community of Kiirua $\left(0.166^{\circ} \mathrm{N}, 37.6^{\circ} \mathrm{E}\right)$ in eastern Kenya. Data collection took place in May through August, 2011 and 2013. All participants in the study in 2013 had participated in the 2011 study and were members of the Muchui Women's Group, a group with whom Farmers Helping Farmers has established a close working relationship over the past 20 years. In 2011, 38 women were selected for study participation. The criteria required the women to be between the ages of 25 and 50, be the primary cook in their household, attend a respiratory assessment, complete an in-home 
administered questionnaire, and wear thermal absorption tubes when in cookhouses. In 2013 not all women were able to participate in all aspects of the study. Twenty-five women participated in home interviews, 24 had respiratory assessments, and 29 successfully completed the thermal desorption tube (TDT) assignment.

\subsection{Indoor air quality}

Women were asked to wear a thermal desorption tube (Tenax TA, Markes International) for a period of four days while in their cookhouse. A thermal desorption tube is a small, stainless steel tube that clips onto the collar of the participants' shirt and acts as personal exposure monitors for this exposure period. These tubes do not interfere with daily activities, require little training to operate and require no electricity to function. Thermal desorption tubes measure VOC's by passive diffusion. Women were asked to record the amount of time (to the minute) they spent in the cookhouse per day. Thermal desorption tubes were kept in two sealed $\operatorname{Ziploc}^{\odot}$ bags to prevent sampling while women were not in cookhouses.

All TDTs were sent to the Atlantic RURAL Centre's (ARC), Environmental Health Laboratory for analysis for volatile organic compounds (VOCs) and were analyzed using gas chromatography [13].

\subsection{Wood use}

Women were asked a prepared series of questions about the woman's family, farm, cooking, type(s) of cooking fuel(s) used, money spent on cooking fuel, wood collection, their general health and the health of any preschool-age children that lived in the household. Farm characteristics were used to determine whether women had a similar socioeconomic status in both years. A translator was used to read the questions and provide answers. Information also collected concerning the size and venting of the cookhouse.

\subsection{Respiratory health}

In addition to completing in-home questionnaires, women completed a general health assessment and a basic respiratory assessment which included three spirometer (Grace Medical Marketing Inc.) readings within 5\% of each other. Parameters measured included forced vital capacity (FVC), forced expiratory volume (FEV1), FEV1/FVC, peak expiratory flow (PEFR), and forced exhalation of the remaining 25-75\% of the forced vital capacity (FVC25-75). Predicted values were based on African Americans as data for Kenyans were not available. The women also had their pulse, blood oxygen saturation, height and weight recorded.

\subsection{Data analysis}

If data were normally distributed, or data could be transformed to normality, most comparisons between 2011 and 2013 were tested with paired t-tests. Otherwise, if data could not be transformed, tests were made Mann-Whitney U tests. 


\section{Results}

Twenty-five of the 38 women completed the survey results in 2013. Three of the women in 2011 already had installed energy efficient stoves and are excluded from all analysis concerning air quality or cookstoves. Cookhouse characteristics remained the same. In 2011, five women had stoves in their house while one was in the process of being built. Measurements of the remaining cookhouses indicated that cookhouses were located $2.8 \pm 1.6 \mathrm{~m}$ from the house and were $3.1 \pm 0.8 \mathrm{~m}$ long, $2.4 \pm 0.5 \mathrm{~m}$ wide, and $2.1 \pm 0.3 \mathrm{~m}$ high. Approximately $26 \%$ had no window and used only the door for ventilation.

\subsection{Indoor air quality}

Preliminary analysis suggests there was no difference in air quality after the installation of energy efficient stoves based on analysis of volatile chemicals to which women were exposed. While there was no significant difference for most chemicals, the concentration of two decreased between years $(1,1,1$ trichloroethene, o-xylene) and three increased (p-xylene, 1,1,2,2tetrachloroethane, 1,4-dichlorobenzene). A total of 26 VOC species were detected; table 1 provides an overview of both years combined.

\subsection{Wood use}

Although the indoor air quality of cookhouses did not appear to change as the result of conversion to energy-efficient stoves, women appeared to benefit by spending less money for extra fuel and less time in wood collection. Women spent an average of $562( \pm 423.2)$ Kenyan shillings per week on fuel in 2011 but only $254( \pm 72.3) \mathrm{Ksh}$ in $2013(\mathrm{p}<0.01)$. They also spent significantly less time in cookhouses, fig. 1 . The number of times that women collected wood per week and the time spent collecting wood did not change significantly, fig. 1, although the total time spent in wood collection (number of times collecting times number of hours collecting) per week was less in 2013 than in 2011 (2011: 7.3 $\pm 6.29 \mathrm{~h}$ vs 2013: $4.9 \pm 4.18 \mathrm{~h}, \mathrm{p}=0.054)$.

\subsection{Respiratory health}

General health characteristics were similar for women in 2011 and 2013 (table 2). Oddly, for the 24 women repeating the interviews, age increased by 3.6 years. Weight increased over the two years while oxygen saturation levels declined slightly. All other measurements taken remained unchanged, table 2.

Women differed in self reporting of general illnesses for both themselves and their children in 2011 and 2013. When asked "Which of the following problems have you had in the past six months?", a greater proportion of women reported having colds, coughs, difficulty breathing and eye irritation in 2011 than in 2013, fig. 2(a), although the difference between years was significant only for coughs. Women also reported that their children had significantly fewer colds and coughs during the previous six months in 2013 than in 2011, fig. 2(b). 
Table 1: Descriptive statistics of VOC species personal exposure.

\begin{tabular}{|c|c|c|c|c|}
\hline \multirow[b]{2}{*}{ VOC species } & \multicolumn{4}{|c|}{ Metric $\left(\mu g / m^{3}\right)$} \\
\hline & Mean & Std Dev & Max & Min \\
\hline Chloroform & 6.4 & 14.7 & 63.0 & 0.0 \\
\hline Tetrahydrofuran & 57.2 & 219.2 & 1184.7 & 0.0 \\
\hline 1,2-dichloroethane & 13.6 & 43.8 & 179.0 & 0.0 \\
\hline 1,1,1-trichloroethane & 24.6 & 65.4 & 315.5 & 0.0 \\
\hline Benzene & 126.7 & 84.0 & 313.5 & 0.0 \\
\hline Carbon tetrachloride & 37.4 & 89.4 & 420.5 & 0.0 \\
\hline Fluorobenzene & 21.3 & 34.0 & 160.5 & 0.0 \\
\hline Methyl methacrylate & 9.3 & 30.2 & 158.0 & 0.0 \\
\hline 1,1,2-trichloroethane & 2.9 & 14.1 & 76.0 & 0.0 \\
\hline Toluene & 85.3 & 109.3 & 574.8 & 0.0 \\
\hline 1,2-dibromoethane & 2.0 & 3.9 & 12.7 & 0.0 \\
\hline Ethylbenzene & 12.3 & 30.6 & 162.2 & 0.0 \\
\hline m-Xylene & 36.2 & 32.9 & 97.4 & 0.0 \\
\hline p-Xylene & 38.4 & 33.6 & 109.7 & 0.0 \\
\hline Styrene & 22.5 & 28.9 & 82.9 & 0.0 \\
\hline 1,1,2,2-tetrachloroethane & 9.9 & 10.6 & 36.6 & 0.0 \\
\hline o-Xylene & 14.4 & 16.0 & 56.2 & 0.0 \\
\hline Bromobenzene & 4.0 & 14.5 & 73.8 & 0.0 \\
\hline 2-chlorotoluene & 19.6 & 28.5 & 114.6 & 0.0 \\
\hline 1,2,3-trimethylbenzene & 1.7 & 4.9 & 20.0 & 0.0 \\
\hline 1,4-dichlorobenzene & 23.5 & 37.3 & 121.4 & 0.0 \\
\hline sec-Butylbenzene & 4.6 & 20.0 & 104.8 & 0.0 \\
\hline 1,3-dichlorobenzene & 2.9 & 7.4 & 24.9 & 0.0 \\
\hline Nitrobenzene & 15.8 & 28.6 & 99.3 & 0.0 \\
\hline 1,2,4-trichlorobenzene & 1.4 & 4.0 & 18.0 & 0.0 \\
\hline Naphthalene & 17.6 & 26.5 & 90.8 & 0.0 \\
\hline
\end{tabular}




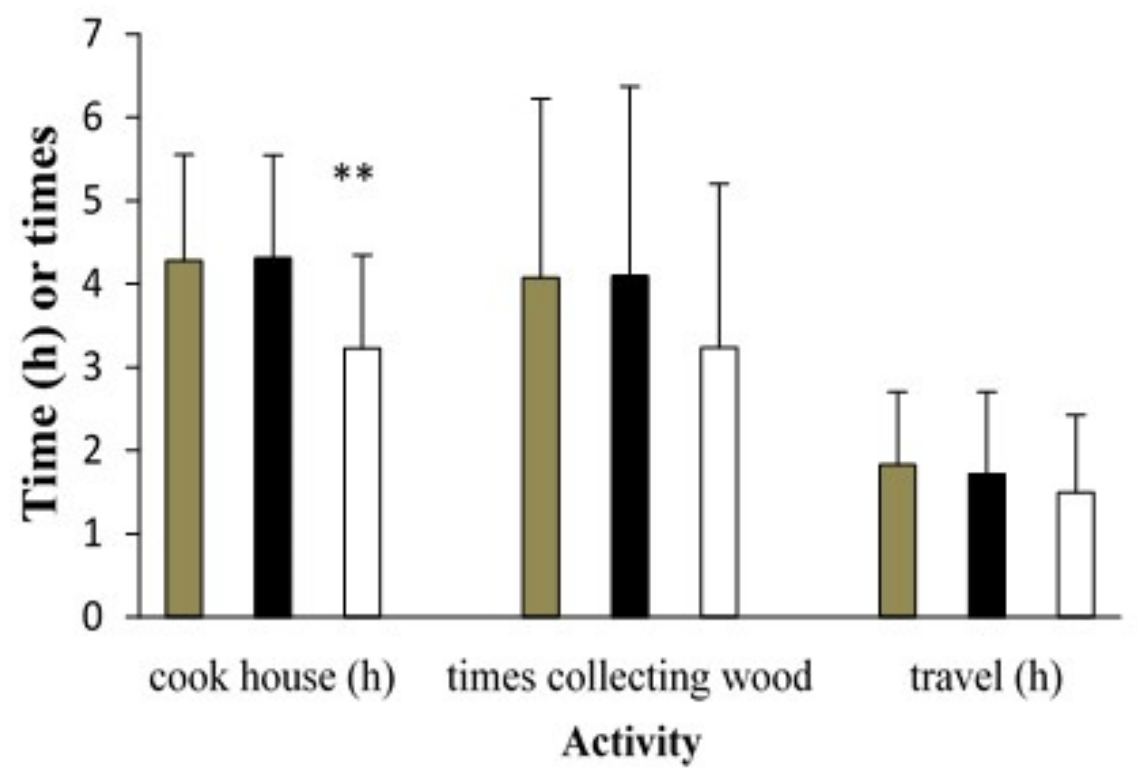

Figure 1: The time spent in the cookhouse, number of times collecting wood, and time spent travelling to collect wood by all women in 2011 (grey) and the 24 women for which data were collected in 2011 (black) and repeated in 2013 (white).

Table 2: General health characteristics of women in 2011 retested in 2013 (mean \pm std). Significance levels: $+p<0.05++p<0.01$.

\begin{tabular}{lccc}
\hline & 2011 & 2013 & prob \\
\hline Age & $36.6 \pm 6.36$ & $40.2 \pm 7.36$ & ++ \\
Height (m) & $1.60 \pm 0.06$ & $1.60 \pm 0.06$ & \\
Body mass (kg) & $65.8 \pm 9.83$ & $69.8 \pm 10.18$ & ++ \\
Resting respiratory rate & $20.3 \pm 4.29$ & $18.8 \pm 2.64$ & \\
Resting pulse rate & $85.5 \pm 16.28$ & $89.8 \pm 16.28$ & \\
Systolic pressure (mmHg) & $122.9 \pm 21.59$ & $120.0 \pm 17.17$ & \\
Diastolic pressure $(\mathrm{mmHg})$ & $81.5 \pm 13.89$ & $82.5 \pm 13.22$ & \\
Oxygen saturation $(\%)$ & $98.3 \pm 0.92$ & $97.5 \pm 1.38$ & + \\
\hline
\end{tabular}



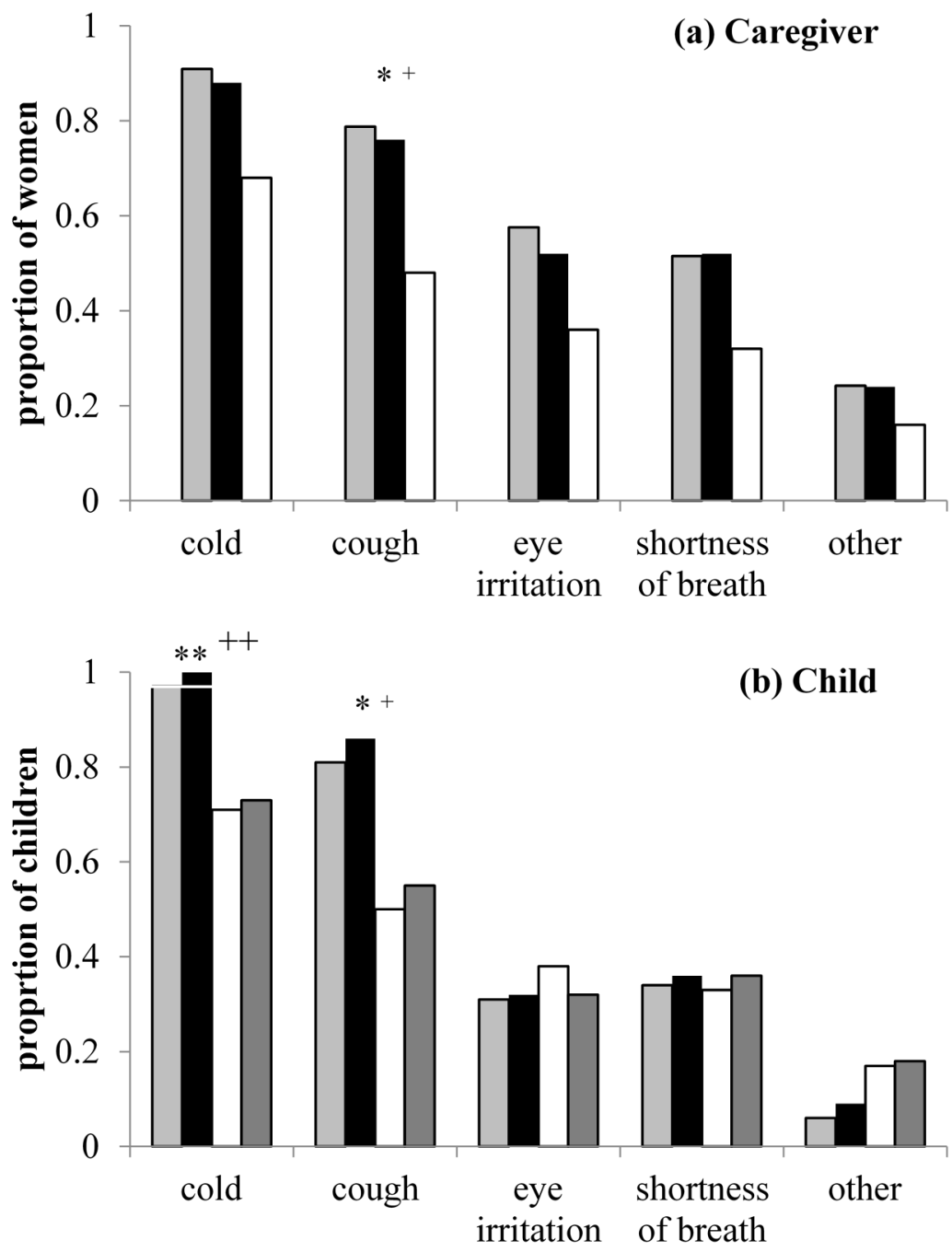

Figure 2: $\quad$ Proportion of (a) caregiver and (b) children suffering from various illnesses in the previous six months. Significance levels: $+\mathrm{p}<0.05++$ $\mathrm{p}<0.01$ (all participants) and $* \mathrm{p}<0.05 * * \mathrm{p}<0.01$ (participants who were retested).

Spirometry tests confirmed that respiratory function increased after the installation of energy-efficient cookstoves. In both 2011 and 2013 the majority of observed values for lung assessments were lower than predicted the values for African American women of similar size, table 3. However, in each case, the percent predicted was higher in women who were retested in 2013. Measured values of FEV1/FVC, PEFR1 and FEF25-75 were also greater in women in 2013 than in 2011. 
Table 3: Spirometry comparison between women in 2011 retested in 2013 ( $\mathrm{n}=$ 24; mean \pm std). Significance levels: $+\mathrm{p}<0.05++\mathrm{p}<0.01$.

\begin{tabular}{ccccc}
\hline & & 2011 & 2013 & prob \\
\hline FEV & measured & $2.74 \pm 0.51$ & $2.87 \pm 0.41$ & \\
& predicted & $3.39 \pm 0.20$ & $3.36 \pm 0.26$ & \\
& $\%$ predicted & $81.0 \pm 16.1$ & $85.6 \pm 11.2$ & + \\
\hline FEV1 & measured & $2.29 \pm 0.46$ & $2.58 \pm 0.43$ & \\
& predicted & $2.79 \pm 0.17$ & $2.75 \pm 0.22$ & \\
& \% predicted & $82.2 \pm 16.8$ & $93.9 \pm 15.6$ & ++ \\
\hline FEV1/FVC & measured & $0.85 \pm 0.11$ & $0.90 \pm 0.09$ & ++ \\
& predicted & $0.85 \pm 0.01$ & $0.85 \pm 0.01$ & \\
& \% predicted & $100 \pm 12.7$ & $106.0 \pm 10.2$ & ++ \\
\hline PEFR1 & measured & $3.85 \pm 1.45$ & $5.26 \pm 1.59$ & ++ \\
& predicted & $6.26 \pm 0.25$ & $6.23 \pm 0.33$ & \\
& \% predicted & $61.4 \pm 22.2$ & $84.6 \pm 25.6$ & ++ \\
\hline FEF25-75 & measured & $2.65 \pm 1.05$ & $3.32 \pm 0.96$ & ++ \\
& predicted & $3.63 \pm 0.29$ & $3.62 \pm 0.21$ & \\
& $\%$ predicted & $73.8 \pm 30.7$ & $91.2 \pm 27.2$ & ++ \\
\hline
\end{tabular}

\section{Discussion}

In this study we assessed air quality, wood use, and the respiratory health of a population of rural Kenyan women before and after the installation of more energy efficient stoves. It was determined that the air quality to which women were exposed did not change significantly but that they spent less time in cookhouses. They also spent less time gathering wood and spent less money on extra fuel during the week. Using less wood, and spending less time in cookhouses, may explain the improvement in respiratory health observed after energy efficient stoves were installed.

\subsection{Indoor air quality}

There were no consistent differences in the number and concentration of volatile organic compounds to which women were exposed. Research by Dohoo et al. [13], in which they used similar thermal desorption tubes to quantify levels of VOCs to compare VOC exposure for women using biogas stoves and traditional stoves, was carried out approximately $150 \mathrm{~km}$ from our study site. Both populations live in rural areas of Kenya, share similar lifestyles, and use similar cookstoves. They also found no difference in VOC exposure although did find a difference gas profiles.

Cookhouse characteristics are thought to impact the levels of wood smoke and toxins to which participants were exposed. In both 2011 and 2013 ventilation structures such as windows and doors were left open. The intent of chimney installation in 2013 was to increase ventilation of smoke out of the cookhouse and decrease the wood necessary for cooking. However, in 2013, it was also observed 
that most stove doors were being left open while the stove was in use, permitting smoke to escape into cookhouse. This may have been the result of oversized wood (i.e. not cut sufficiently to fit in the firebox) or getting more heat out of open stoves. Regardless, leaving the doors of the cookstove open during the sampling period is thought to have contributed to the increased VOC concentrations measured in 2013. With proper use, women should theoretically at least, be exposed to fewer toxins when they are in cookhouses.

\subsection{Wood use}

Although there were no differences in VOC levels in cookhouses having more efficient stoves, there appeared to be significantly less wood used, implying that stoves were more fuel efficient. In self-reporting surveys, women spent less money per week on extra fuel, spent less time collecting wood each week, and spent less time in the cookhouse each day.

Fuel use and collection constitute major monetary and time costs for women using traditional cookstoves. In many cases, wood makes up a substantial source of energy, and cooking and heating water may consume more than $70 \%$ of wood used in Central Africa [14]. Using more efficient stoves, the amount of wood required decreases [e.g., 15-18; although see 19] and women, who often supplement the wood that they collect with fuel they must purchase, reported substantial cost savings [16-18]. This can represent significant savings for women who may spend $15-20 \%$ of their income on fuelwood [18].

Time costs are also important. Typically the burden of collecting firewood is borne by women and children who, based on this study, can spend over 7 hours per week of their time in collecting activities in addition to the 4 hours per day in cookhouses. Women must prioritize their time; the less time spent preparing the stove and/or gathering fuel for cooking the more time they have free for other activities which may include work, or raising children [20]. An increased amount of time collecting firewood is also correlated to a number of health issues. In India, women may experience stiff necks, back problems, and headaches [21]. In Kenya, women collecting less wood reported fewer back problems [22].

\subsection{Respiratory health}

Possibly because of spending less time in cookhouses, the respiratory health of women using energy-efficient cookstoves improved. They reported fewer illnesses for themselves and their children over the previous six months. Women have also reported a lower incidence of disease after the adoption of better cookstoves in the Honduras [23], Ghana [24], Nepal [25] and Kenya [16]. However, the selfreporting of various illnesses is difficult to interpret as it could have happened because 1) women and children really did experience lower illnesses or 2) women reported fewer illnesses because of expectations.

Spirometry values, which provide a more objective measure of lung function, confirm that lung functioning did improve. In our study, women were significantly closer to predicted values for all spirometry values, and measured values for FEV1/FVC, PEFR1, and FEF25-75 were higher after cooking on energy-efficient 
stoves for approximately 20 months. There was no indication that women, before or after the installation of new stoves, suffered from COPD, defined as a ratio of FEV1 to $\mathrm{FVC}<0.70$ [26].

While there have been many studies of indoor air quality in developing countries, including some comparing IAQ before and after stove improvements [e.g., 27-30], few studies have simultaneously examined effects on human health. Notably, Guatemalan women reported fewer headache and less eye discomfort after installation of improved wood burning stoves [31] while the use of cleaner household fuels coincided with a $31 \%$ decrease in childhood mortality in subSaharan Africa [32]. In this study, we documented improvements in self-reported respiratory health of women and children, and the respiratory health of women as determined by spirometry readings, after adoption of more efficient stoves.

\section{References}

[1] Bruce, N., Perez-Padilla, R. \& Albalak, R., The health effects of indoor air pollution exposure in developing countries. Geneva, Switzerland: World Health Organization, 2002.

[2] Naeher, L.P., Brauer, M., Lipsett, M., Zelikoff, J.T., Simpson, C.D., Koenig, J.Q. \& Smith, K.R., Woodsmoke health effects: a review. Inhalation Toxicology 358, pp. 619-624, 2007.

[3] Smith, K.R., Mahta, S. \& Maeusezahl-Feuz, M., Indoor air pollution from household use of solid fuels: comparative quantification of health risks. Global and regional burden of disease attributional to selected major risk factors, eds. M.L.A Ezzati, A. Rodgers \& C.J.L. Murray, Geneva, Switzerland: World Health Organization, pp. 1435-1493, 2004.

[4] World Health Organization (WHO), Indoor air population and health. WHO Media Center. Retrieved online from http:/www.who.int/mediacentre/ factsheets/ fs292/en/, 2004.

[5] Ndegwa, G., Breuer, T. \& Hamhaber, J., Woodfuels in Kenya and Rwanda: powering and driving the economy of the rural areas. Rural 21, pp. 26-30, 2011.

[6] Rouse, J., Improved biomass cookstove programmes: fundamental criteria for success. MA Rural Development Dissertation: The University of Sussex, 1999.

[7] Zelikoff, J.T., Chem, L.C., Cohen, M.D. \& Schlesinger, R.B., The toxicology of inhaled woodsmoke. Journal of Toxicology and Environmental Health 5, pp. 269-282, 2002.

[8] Boy, E., Bruce, N. \& Delgado, H., Birth weight and exposure to kitchen woodsmoke during pregnancy. Environmental Health Perspectives 110, pp. 109-114, 2002.

[9] Johnson, A.W. \& Aderele, W.I., The association of household pollutants and socioeconomic risk factors with the short-term outcome of acute lower respiratory infections in hospitalized pre-school Nigerian children. Annals of Tropical Paediatrics 12, pp. 421-432, 1992. 
[10] Regalado, J., Pérez-Padilla, R., Sansores, R., Ramirez, J.I.P., Brauer, M., Paré, P. \& Vedal, S., The effect of biomass burning on respiratory symptoms and lung function in rural Mexican women. American Journal of Respiratory and Critical Care Medicine 174, pp. 91-95, 2006.

[11] Warwick, H. \& Doig, A., Smoke - the killer in the kitchen. International Technology Development Group (ITDG), 2004.

[12] World Food Program, Fighting hunger worldwide. http://documents.wfp.org/stellent/groups/public/documents/ communications/wfp220666.pdf, 2010.

[13] Dohoo, C., Guernsey, J.R., Gibson, M.D. \& VanLeeuwen, J. Impact of biogas digesters on cookhouse volatile organic compound exposure for rural Kenyan farm women. Journal of Exposure Science and Environmental Epidemiology 2013, pp. 1-8, 2013.

[14] Johnson, N.G. \& Bryden, K.M., Factors affecting fuelwood consumption in household cookstoves in an isolated rural West African village. Energy 46(1), pp. 310-321, 2012.

[15] Adkins E., Oppelstrup, K. \& Modi V., Rural household energy consumption in the millennium villages in Sub-Saharan Africa; Energy for Sustainable Development 16, pp. 249-259, 2012.

[16] Person, B., Loo, J.A., Owuor, M., Ogange, L., Jefferds, M.E.D. \& Cohen, A.L., "It Is Good for My Family's Health and Cooks Food in a Way That My Heart Loves": Qualitative findings and implications for scaling up an improved cookstove project in rural Kenya. Int. J. Environ. Res. Public Health 9, pp. 1566-1580, 2012.

[17] Vaccari, M., Vitali, F. \& Mazzù, A., Improved cookstove as an appropriate technology for the Logone Valley (Chad-Cameroon): Analysis of fuel and cost savings. Renewable Energy 47, pp. 45-54, 2012.

[18] Berrueta, V.M., Edwards, R.D. \& Masera, O.R., Energy performance of wood-burning cookstoves in Michoacan, Mexico. Renewable Energy 33(5), pp. 859-870, 2008.

[19] Granderson, J., Sandhu, J.S., Vasquez, D., Ramirez, E. \& Smith, K.R., Fuel use and design analysis of improved wood burning cookstoves in the Guatemalan Highlands. Biomass and Bioenergy 33(2), pp. 306-315, 2009.

[20] Biran, A., Abbot, J. \& Mace, R., Families and firewood: a comparative analysis of the costs and benefits of children in firewood collection and use in two rural communities in sub-Saharan Africa. Human Ecology 32(1), pp. $1-25,2004$.

[21] Parikh, J., Hardships and health impacts on women due to traditional cooking fuels: A case study of Himachal Pradesh, India. Clean Cooking Fuels and Technologies in Developing Economies, Energy Policy 39(12), pp. 7587-7594, 2011.

[22] Dohoo, C., VanLeeuwen, J., Guernsey, J.R., Critchley, K. \& Gibson, M., Impact of biogas digesters on wood utilisation and self-reported back pain for women living on rural Kenyan smallholder dairy farms. Global Public Health 8(2), pp. 221-235, 2013. 
[23] Clark, M.L., Reynolds, S.J., Burch, J.B., Conway, S., Bachand, A. \& Peel, J.L., Indoor air pollution, cookstove quality, and housing characteristics in two Honduran communities Environmental Research 110(1), pp. 12-18, 2010.

[24] Burwen, J. \& Levine, D.I., A rapid assessment randomized-controlled trial of improved cookstoves in rural Ghana. Energy for Sustainable Development 16(3), pp. 328-338, 2012.

[25] Singh, A., Tuladhar, B., Bajracharya, K., \& Pillarisetti, A., Assessment of effectiveness of improved cookstoves in reducing indoor air pollution and improving health in Nepal. Energy for Sustainable Development 16(4), pp. 406-414, 2012.

[26] Pauwels, R.A., Buist, A.S., Calverly, P.M., Jenkins, C.R. \& Hurd S.S., GOLD Scientific Committee. Global strategy for the diagnosis, management, and prevention of chronic obstructive pulmonary disease. NHLBI/WHO Global Initiative for Chronic Obstructive Lung Disease (GOLD) Workshop summary. Am. J. Respir. Crit. Care Med. 163(5):pp. 1256-1276, 2001.

[27] Masera, O., Edwards, R., Armendáriz, C., Berrueta, V., Johnson, M., Rojas, L. \& Riojas-Rodríguez, H., Impact of "Patsari" improved cookstoves on indoor air quality in Michoacan, Mexico. Energy For Sustainable Development 11, pp. 45-56, 2007.

[28] Cynthia, A.A., Edwards, R.D., Johnson, M., Zuk, M., Rojas, L., Jimenez, R.D., Riojas-Rodriguez, H. \& Masera, O., Reduction in personal exposures to particulate matter and carbon monoxide as a result of the installation of a Patsari improved cookstove in Michoacan Mexico. Indoor Air 18, pp. 93105, 2008.

[29] Smith-Sivertsen, T., Díaz, E., Pope, D., Lie, R.T., Díaz, A., McCracken, J., Bakke, P., Arana, B., Smith, K.R. and Bruce, N., Effect of reducing indoor air pollution on women's respiratory symptoms and lung function: the RESPIRE randomized trial, Guatemala. Am. J. Epidemiol. 170(2), pp. 211220, 2009.

[30] Fitzgerald, C., Aguilar-Villalobos, M., Eppler, A.R., Dorner, S.C., Rathbun, S.L. \& Naeher, L.P., Testing the effectiveness of two improved cookstove interventions in the Santiago de Chuco Province of Peru. Science of The Total Environment 420, pp. 54-64, 2012.

[31] Diaz, E., Smith-Sivertsen, T., Pope, D., Lie, R.T., Diaz, A., McCracken, J., Arana, B., Smith, K.R. \& Bruce, N., Eye discomfort, headache and back pain among Mayan Guatemalan women taking part in a randomised stove intervention trial. J. Epidemiol. Community Health 61, pp. 74-79. 2007.

[32] Gakidou, E., Oza, S., Vidal Fuertes, C., Li AY, Lee, D.K., Sousa, A., Hogan, M.C., Vander Hoorn, S. \& Ezzati M., Improving child survival through environmental and nutritional interventions: the importance of targeting interventions toward the poor. JAMA 298(16), pp. 1876-1887, 2007. 